\title{
LOS PRINCIPIOS DISPOSITIVO E INQUISITORIO DEL PROCESO CIVIL
}

La oportunidad de una reforma de los códigos de procedimientos, especialmente el de procedimientos civiles, incita a recordar y replantear el antiguo problema de la verdad de los hechos y la investigación de los mismos por el juez en el proceso civil. Tema siempre latente es el de establecer la justicia en los "intereses privados en confilicto". No obstante el avance de los estudios teóricos sobre el proceso civil, aún acostumbramos pensar tal proceso como una prolongación de los conflictos que surgen en el derecho civil.

Este lenguaje revela la antigua división del derecho en público y privado que todavia domina, a pesar de que serios estudios afirman que no hay razones para creer en tal división en el sentido tradicional. Sin embargo, no extraña el hecho que entre nosotros aún se discuta si el proceso civil es rama de derecho público o privado y con seguridad muchos abogados y procesalistas ostentan "fuertes razones" para pensar que en tanto en el proceso civil "se ventilan intereses de particulares" éste es rama de derecho privado, concepción que sostiene que el proceso civil debe estar construido sobre la base del principio dispositivo que en última instancia hace el juez un 'observador' del cumplimiento de las reglas del juego procesal por las partes.

Otros piensan que el proceso civil es rama del derecho público; o para decirlo con Böcking, el primero en considerar el proceso civil "como lo que se abre al derecho público" (1). A una y otra tendencia se han

* El presente trabajo es un resumen de los cap. I, II V III de la obra inédita Determinación y fundamento de la verdad como concepto estructural del proceso civil, del mismo autor.

l BOCKING, Esquema de lecciones sobre el proceso civil común alemán, cit. por Von Bulow Oskar, Excepciones y presupuestos procesales, Bs. As., Ed. EJEA, 1964, p. 2. unido las ideologías sobre la naturaleza de la relación entre individuo y Estado. Asi el proceso civil "privadista" correspondería a los estados democráticos liberales; y el proceso civil "publicista" pertenecería a la concepción del estado totalitario. De tal modo, según el proceso civil "privadista" el proceso se desarrolla sobre principios que garantizan la 'verdad' de los hechos hasta un cierto grado, limitando al juez no sólo el tema de su conocimiento sino incluso los medios para lograrlo. En este contexto se habla entonces de la 'verdad formal' que puede ser diferente a la 'verdad material' (o real) de los hechos.

\section{EL PRINCIPIO DISPOSITIVO}

\section{Las Máximas Tradicionales del Proceso Civil}

Secundum Allegata et Probata PUartium ludex ludidcare debet. Nemo ludex Sine Actore. Ne Procedat ludex Ex Officie. Ne eat ludex Ultra Petita Partium, máxima que indica que el proceso se desarrollará dentro de ciertos limites que el juez'no puede sobrepasar. La máxima en cuestión delimita "la extensión de la materia sobre la que el juez debe pronunciarse, y esto en un doble sentido: impidiendo que el órgano jurisdiccional falle sobre puntos no sometidos a su competencia y prohibiendo igualmente que algunas de las cuestiones propuestas queden sin solución"(2). Esto es así porque se actúan derechos subjetivos, o sea facultades de las partes; de ahi que no baste que el hecho sea cierto sino que se pida por su titular. Incluso cualquier olvido u omisión, aunque después se con-

2 GUASP, Jaime, Juez y hechos en el proceso civil. Una crítica del derecho de disposición de las partes sobre el material de hecho del proceso, Barcelona, Ed. Bosch, 1943, pág. 35. 
firmara su acuerdo con la ley, no puede ser anotado por el juez de oficio.

La última máxima que combina perfectamente con la anterior es la que afirma Quot Non est in Actis, non ist in Mundo, lo que significa que "ningún hecho puede llegar sino a través de las partes y por consiguiente no existe, procesalmente hablando, si no ha sido incluido en una declaración formulada por alguna de aquélias" (3). La 'realidad' con la cual el juez se enfrenta está determinada por las partes; el conocimiento del juez se limita así a los hechos "in actis", aunque él los conozca "in mundo". "Lo que pone de relieve que tanto la prueba como precedentemente la alegación son, respecto a los hechos y en términos generales, límites puestos al conocimiento oficial del juez y a la posibilidad de que tales hechos sean apreciados por él" (4).

\section{Función del Juez en el Proceso Civil Dispositivo.}

\section{Calamandrei la expresa poéticamente:}

"Juez, tú no tienes que fatigarte para encontrar argumentos, porque solamente estás llamado a escoger entre los buscados por nosotros los abogados, que realizamos por ti, el duro trabajo de excavar, y para mejor meditar tu elección, tienes el deber de sentarte en tu cómodo sillón... Tú eres ¡Oh Juez! la olímpica inmovilidad que sin prisa, espera" (5).

La base de esta expresión es en realidad la concepción de que

"el proceso es negocio privado de las partes, ellas conducen soberanamente, detienen cuando les plaz(a) entorpecen $\sin$ consecuencias relegando al juez a un plano secundario de simple observador, a quienes los litigantes manejan según sus conveniencias, astucia o habilidad" (6).

Se establece así una situación del juez realmente humillante, pues la configuración de este tipo de proceso puede llevarlo, y casi siempre lo lleva, a fallar como 'verdad' - probada procesalmente, verdad formal- lo que en realidad no es tal; por ello Guasp ha resaltado la “inminencia de un ritualismo incompatible con la mejo-

3 UGASP, op. cit., pág. 39.

4 Ibídem.

5 CALAMANDREI, Piero, Elogio a los jueces hecho por un abogado, Bs. As., Ed. EjEA, 1956, p. 389.

6 RODRIGUEZ, J.J., Justicia Civil, Colombia, s/f, p. 104. ra de la institución procesal que exige ir continuamente eliminando las llamadas verdades formales para dejar paso a la única verdad que existe, la que concuerda con la realidad" (7).

Ugo Rocco, interpretando la máxima Narra mihi factum dabo tibi ius, expresa: "ciertamente si el hecho conocido por el magistrado es diverso del afirmado por la parte como constitutivo de la base de su propio derecho, no puede aquél tomarlo como fundamento de su resolución" por la fuerza de la máxima anotada "en virtud de la cual todo to que mira al hecho se deja a disposición de las partes" (8). Entre otros, como Chiovenda y Goldschmidt, Rosemberg afirma que el principio dispositivo o princ:pio de pasividad del juez "debe buscarse en el egoísmo de las partes y en la contradicción que hay entre sus intereses, así como en la carencia de un interés público por parte del Estado en esta clase de litigios y porque la verdad puede obtenerse mejor por el poder de las partes que no por la investigación del juez" (9). O expresiones que como las del español Miguel y Romero apuntan más bien a la naturaleza de los jueces de raza latina para quienes no aconseja facultades amplias en el proceso pues, "a medida que al juez de raza latina se le aumenta sus poderes y su interés en el proceso irá perdiendo su imparcialidad y rectitud, virtudes preciosas que quedarán sacrificadas ante el deseo instintivo de que prevalezca su juicio, o lo que es peor aún, su prejuicio, del cual ningún hombre se puede considerar libre" (10).

La posición de Adolfo Wach, a la que calificamos como "purista", se sustenta sobre la presunción de 'buena fe' de las partes en el litigio y por tanto "enredos y toda conducta inconveniente deben impedirse y alejarse de oficio", pero no hay que olvidar que "el objeto del litigio es de naturaleza puramente jurídicoprivada: una relación jurídica sólo entre el demandante y el demandado y por ello la disposición de las partes tiene que influir en el proceso" (11). Wach se burla un poco del deseo "juvenil" y lleno de "vi-

7 GUASP, op. cit., pág. 46.

8 ROCCO, Ugo, Teoría general del derecho procesal civil, México, Ed. Porrúa, 1959, p. 224.

9 ROSEMBERG, Lehrbuch des deutschen zivilprozessrecht, cit. por Guasp, op. cit., pág. 57.

10 MIGUEL y ROMERO, Principios del moderno derecho procesal civil, cit. por Guasp, op. cit., pág. 61.

11 WACH, Adolfo, Conferencias sobre la ordenaza procesal civil alemana, Bs. As., Ed. EJEA, 1958. 
vacidad y de calor" de los que modernamente postulan la construcción del proceso civil sobre el principio de la Verdad Material. Wach aclara:

"Ciertamente la verdad es siempre una sola, y no podemos obligar al juez en lo civil a considerar como verdadero algo que no lo es. Sin embargo, podemos y debemos obligarlo a tratar como verdaderas, muchas cosas de cuya veracidad de ningún modo está convencido.

La comprobación de la verdad... no es la finalidad del proceso civil y no puede serlo. Esa comprobación es un resultado contingente. La verdad material es sólo imaginable como finalidad del proceso, en un procedimiento oficial, esto es, en un proceso que no sólo da margen a una reconstrucción completa de la situación de hecho sino que establece la "máxima de la libre investigación” como un deber inicial de los órganos del Estado. Y ello sólo puede suceder cuando el objeto del proceso es de interés público. En el proceso civil, la naturaleza jurídico-privada de ese objeto elimina la "máxima de libre investigación" $y$, con esto, la finalidad del proceso consiste en la comprobación objetiva del verdadero estado de cosas" (12).

Por último, hay que entender "el verdadero estado de cosas", como aquella que se da en el proceso civil, cuyo objeto es de naturaleza privada, es decir, el cumplimiento puro, en la sana intención de Wach, de la máxima quot non est in actis, non ist in mundo.

\section{El sistema de Carnelutti}

La expresión más sólida y sistemática del proceso civil dispositivo la estableció Francisco Carnelutti. Según él mismo afirma los conceptos de su sistema los toma de la filosofía y por ello escribe "nunca he trabajado tanto por el Derecho como cuando me he evadido de los límites de su ciencia" (13).

Como bien expresa Giacomo Augenti en el apéndice a la edición de "La Prueba Civil", Carnelutti "destruye el mito caro a los procesalistas penales de la búsqueda de la verdad material". Así, por ejemplo, una exacta definición de la prueba en el proceso civil dispositivo es la que dice:

\section{Ibidem.}

13 CARNELUTTI, Francisco, La prueba civil, Bs. As., Ed. Arayú, 1955, pág. 40. "el lenguaje corriente, probar significa demostrar la verdad de una proposición afirmada. Ahora bien, en el campo jurídico la comprobación de los hechos controvertidos por parte del juez puede no derivar de la búsqueda de su verdad, sino de los procesos de fijación formal... Si la ley comprende tales procesos bajo el nombre de prueba, ello significa que el contenido propio del vocablo en el lenguaje jurídico se altera y se deforma. Probar en efecto, no querrá decir ya demostrar la verdad de los hechos discutidos, sino determinar o fijar formalmente los hechos mismos mediante procedimientos determinados" (14).

"Casi toda la doctrina tiene conciencia más o menos sincera de esta alteración del significaco corriente de la palabra prueba, y tras haber advertido que prueba es la demostración de la verdad de un hecho, siente casi siempre la necesidad de precisar su significado jurídico completando así la definición: demostración de la verdad de un hecho realizada por medios legales. . o más brevemente, demostración de la verdad legal de un hecho..." (15).

"El conjunto de las normas jurídicas que regulan el proceso de fijación de los hechos controvertidos, constituyen, pues, la institución jurídica de la prueba. Estas normas establecen una primera y más amplia obligación del juez, de contenido negativo: obligación de no poner en la sentencia hechos discutidos que no hayan sido fijados mediante algunos de los procesos queridos por la ley" (16).

“. . la regulación jurídica del proceso de búsqueda de los hechos controvertidos por parte del juez, altera profundamente la función del proceso mismo, el cual no sirve en realidad para conocer los hechos, o sea para establecer su verdad, sino únicamente para conseguir una fijación formal de ellos" (17).

Conviene, sin embargo, recordar ahora que dicha regulación no ha estado jamás informada por el arbitrio y no está ya informada por el prejuicio, sino que se halla constituida según la finalidad (política) de obtener el conocimiento de los hechos controvertidos por el camino más rápido y seguro. La circunstancia de que en un número más o menos grande de casos, tal finalidad falle y de que, pese a ello, los hechos resul-

14 CARNELUTTI, op. cit., pág. 40.

15 Ibid., pág. 44.

16 Ibid., pág. 44-45.

17 Ibid., pág. 53. 
tantes del proceso empleado sean considerados como verdaderos, o más exactamente, sean puestos en la sentencia inclusive si no son verdaderos, impide, desde luego, estimar la verdad como resultado constante del proceso probatorio $y$, por tanto, como su nota esencial, pero en manera alguna como la finalidad que dicho proceso se propone alcanzar y que, correlativamente, determina la estructura del mismo. Cierto que la verdad formal es una no verdad, puesto que verdad no puede haber más que una; pero no puede olvidarse que la verdad formal resulta luego de la verdad material en el promedio de los casos (18).

"Todo esto explica que si respecto de la función, el proceso probatorio difiere profundamente del proceso de búsqueda de la verdad material, no se diferencia en cambio, en modo alguno, por lo que concierne a la estructura, modelada sobre la de aquél; en definitiva, por el lado estructural, el proceso probatorio no es más que un proceso típico o un medio de búsqueda de la verdad de los hechos controvertidos, el cual parece apto para alcanzar la finalidad (la verdad) en la mayoría de los casos" (19).

Esto es realmente una exageración y lo desmiente la diaria experiencia en los tribunales; hay fuertes indicios para creer, como Friedrich, que "se ha confirmado, sin dejar lugar a dudas, que en su relación social casi todos los hombres actúan codeterminados por el interés social y la pasión" (20).

El principio dispositivo y la verdad convencional en el proceso civil son fielmente expresados por Carnelutti cuando dice:

"Un sistema procesal así construído integra un poder de disposición de las partes sobre el material de hecho de la sentencia, y, por tanto, una influencia de la conducta de éstas sobre el contenido de la sentencia misma: las partes pueden, bien callando un hecho real o bien afirmando acordes un hecho imaginario, constreñir al juez a poner en la sentencia una situación de hecho diversa de la realidad" (21).

Sin embargo, esta "disposición" de los hechos por las partes, según Carnelutti, no responde exclusivamen-

\section{Ibidem.}

19 Ibídem.

20 FRIEDRICH, C.], La filosofía del derecho, México, Fondo de Cultura Económica, 1964, pág. 281.

21 CARNELUTTI, op. cit., pág. 9. te a la naíuraleza privada de los intereses en juego y por ello la indiferencia del Estado,

"sino que por el contrario, viene principalmente determinado por un propósito práctivo de aprovechamiento de la iniciativa de las partes para una más rápida y segura posición del hecho conforme a la realidad misma: la pugna de intereses que determina y vivifica el proceso, permite considerar que el hecho silenciado por todas las partes no puede existir y cue el hecho afirmado por todas ellas no puede dejar de ser real, mientras que la posibilidad de esta previsión sea falaz en algún raro caso, no disminuye sensiblemente la destacada ventaja de seguridad y de economía" (22).

No vemos cómo sea posible que se hable de "una segura y más rápida segura posición del hecho conforme a la realidad misma", a no ser que se entienda ficticiamente la "realidad", como parece entenderse: "considerar que el hecho silenciado por todas las partes no puede existir y que el hecho afirmado por todas ellas no puede dejar de ser real". Hay aquí, pues, una reglamentación diferente a base de una explícita aceptación de una escala diferente de valores: la seguridad y la economía.

De esta manera desaparecen los "hechos" como objeto del proceso y adquieren preminencia de tal la pugna de intereses que se encuadra perfectamente en el contexto expresado.

"El sistema descunsa, por tanto, en la previsión de la coincidencia normal entre el punto de equilibrio de los intereses privados contrarios y el interés público en la justa realización de las normas jurídicas $y$, por consiguiente, en la fijación de los hechos en la sentencia según la verdad. Sin embargo, no se excluye que, habida cuenta de la eventual divergencia entre el interés privado y el interés público, cuando el orden jurídico acepta la hipótesis de una fijación en la sentencia de hechos contrarios a la verdad, por efecto de la voluntad de las partes manifestada en el silencio concorde de hechos verdaderos o en la afirmación concorde de hechos no verdaderos, sacrifique voluntariamente el interés público al interés privado prevaleciente. Este planteamiento del princi-

22 Ibid., pág. 11. Carnelutti hace referencia a la "demostración del propósito político del principio dispositivo" que hacen Schmidt, en Lehrbuch deustschen Civilprozessrechts, No 70, pág. 417 y Chiovenda en Principios de derecho procesal civil, 3a. edic., pág. 728. 
pio de disposición sobre la tutela del interés público normalmente realizada mediante las voluntades de los particulares con intereses contradictorios y sobre la excepcional subordinación del interés público a los intcreses privados convergentes de las partes, muestra cómo el principio mismo no es una característica indefectible, sino una directiva de conveniencia clel proceso civil, que puecle ceder ante una directiva opuesta en aquellas materias y para aquellos casos respecto de los cuales, o bien el interés público en cuanto a la realidad do los presupuestos de la sentencia se deje sentir con menos intensidad y exija, en cambio, el sacrificio de los intereses privados contrarios, o bien exista motivo para estimar menor aptitud en las partes para tutelar sus intereses opuestos $y$, con ello, menor probabilidad de que el juego de éstos coincida con la dirección del interés público" (23).

Es ésta la expresión más cabal del principio dispositivo. La fijación del hecho controvertido, para Carnelutti, es una fijación formal, indicando con ello que el juez tiene limitado el campo del conocimiento de los hechos y previamente regulado el proceso de su conocimiento. Tales reglas de percepción y deducción de los hechos por parte del juez constituyen la teoria de la prueba legal y dentro de ella la de verdad legal o formal. Además de la base política que reconoce Carnelutti hay que agregar que

“... corrientes tradicionales y propósitos prácticos concurren en distinta medida y combinación a constituir el sistema vigente, cuya utilidad característica debería consistir en la búsqueda económica y segura para el término medio de los casos, con sacrificio de los casos anormales: todos los límites al poder de búsqueda del juez se inspiran fundamentalmente en el propósito de utilizar las experiencias acumuladas para la eliminación de los errores (seguridad de la búsqueda) o de actos superfluos (economía de la búsqueda), los cuales serían posibles si la búsqueda fuese libre, con daño en conjunto mayor del que podría resultar de la inadaptabilidad de aquellos límites a los casos anomales" (24).

\section{La verdad convencional (formal)}

La regulación del proceso cognoscitivo del juez llevará a aceptar lo que se ha dado en llamar verdad legal, juridica o convencional. En palabras de Carne-

23 Ibid., pág. 12.

24 Ibid., pág. 19. lutti: "se denomina verdad formal, porque conduce a una indagación regulada en las formas, o verdad juridica, porque se la busca mediante las leyes juridicas y no sólo mediante leyes lógicas, y únicamente en virtud de esas leyes juridicas reemplaza a la verdad material" (25). Tal planteamiento, dice Carnelutti, es una metáfora, pues la verdad formal es una no verdad; entonces, el proceso, en su más plena interpretación "legalista", no puede ser considerado "como un medio para el conocimiento de la verdad de los hechos, sino para una fijación o determinación de los propios hechos, que puede coincidir o no con la verdad de los mismos y que permanece por completo independiente de ellos" (26). La formulación del proceso civil dispositivo que hace Carnelutti en la "Prueba Civil", es considerada por el mismo autor como superada: "tal como la escribí no expresa ya mi pensamiento". Pero la evolución que logrará Carnelutti en su sistema de derecho procesal civil consistirá en una construcción más amplia de la sociedad, del estado y del derecho, en la que encontrará una mejor fundamentación, mucho más coherente, el proceso civil sobre la base del principio dispositivo. Carnelutti hace resaltar

"hasta la saciedad que el principio dispositivo no se explica como una dirección del proceso al servicio de la utilidad de las partes sino, por el contrario, sólo como medio para obtener del interés en litigio el mayor rendimiento en cuanto a la justa composición del litigio" (27).

El término "JUSTICIA" tiene, dentro del sistema, un signif́icado muy concreto y jurídico. La justicia es "la conformidad con una regla". Según esto, se resuelve justamente un conflicto de intereses cuando la sentencia es justa. Por ello dice Carnelutti: "la composición será justa cuando sea conforme a la regla que en el proceso se halla de aplicar, y por ello, según los casos, cuando sea conforme al derecho o a la equidad (28). Conforme a esto, el fin del proceso se-

25 Ibid., pág. 21.

26 Ibidem. La expresión "verdad formal" se debe a Moser.

27 CARNELUTTI, Sistema de derecho procesal civil, Bs. As., Ed. UTEHA, 1944, t. II, p. 257.

28 CARNELUTTI, op. cit., t. I, pág. 286. La evidencia de que el Sistema de Carnelutti puede considerarse como una revalorización de la idea privatista del proceso, o por lo menos como "una desconfianza hacia un concepto del proceso a ultranza publicista" es también observada por Allorio, op. cit., t. I, pág. 161 y sgts. 
ría arreglar un conflicto conforme a la justicia; sin embargo, éste no s siempre el resultado. De ahí que exista una real división entre fin y resultado en el proceso civil. División en la cual la justicia cederá el paso a la necesidad de la certeza jurídica, que se concretará en la teoría de la cosa juzgada. En el límite de la discusión teórica y concreta dentro del proceso, frente a la justicia aparece la certeza jurídica, concepto apremiante y necesario para que se constituya la paz en la resolución del conflicto de intereses. Creemos que este es el sentido de las ya famosas palabras de Carnelutti:

\begin{abstract}
"Paz con Justicia. Ni paz sin justicia, ni justicia sin paz. Nada de paz sin justicia, porque el proceso... no tiende a componer el litigio de cualquier modo, sinó según el Derecho. Nada de justicia sin paz, porque el Derecho no se aplica o no se realiza por quien está en conflicto, sino por quien está sobre el conflicto: supra partes, no inter partes, a fin de componer un litigio $y$ no de tutelar un interés" (29).
\end{abstract}

De la misma manera como la justicia es el acuerdo con la norma jurídica, así también la verdad es una cualidad juridica. Carnelutti, al hablar de la verdad y falsedad de las pruebas, dice: "Hablamos de pruebas verdaderas o falsas, queriendo indicar con ello las pruebas que son idóneas para fundar un juicio verdadero o falso" (30). La idoneidad de la que habla Carnelutti es una idoneidad legal, formal. Lo idóneo de la prueba no significa correspondencia con la verdad histórica, sino con el cumplimiento de pautas que la convierten en tal.

La prevención o la eliminación de la falsedad es, también, una prevención o eliminación legal, es decir mediante medios que determina la ley. No es posible una eliminación real, como tampoco es posible una verdad real. Carnelutti llama a la eliminación real, eliminación directa que

\begin{abstract}
"se realiza sustituyendo al estado de hecho resultante de la falsificación, el estado de hecho verdadero; o sea, con la reconstrucción de lo que ha sido suprimido, con el retorno a su estado primitivo de lo que ha sido alterado o con la destrucción de lo que ha sido contrahecho. Pero esta forma de eliminación no se adopta a la falsedad por mentira, que se refiere no al continente sino al contenido de la prueba histórica; en efecto,
\end{abstract}

29 lbid., t. I, pág. 287.

30 Ibid., t. II, pág. 462. cuando, como continente, la pruel)a histórica sea verdad, su destrucción sería un plus en relación con lo que es necesario y suficiente para establecer la verdad, la medida exacta de la eliminación se tiene sustituyendo un contenido por otro, pero esto, físicamente no es posible" (31).

Esto lo llevará a afirmar que "... la falsedad de una prueba es siempre una cualidad jurídica, no sólo una calidad material" (32).

A esia conceptualización de la verdad juridica y de verdad o falsedad de la prueba está unida intimamente la idea de la formación lógica de la sentencia, y a la que con orgullo "cientifico" algunos procesalistas civiles Ilaman "prueba matemática". Couture lo expresa muy bien:

"por concepto de la prueba en materia civil... se entiende un método jurídico de verificación de las proposiciones de las partes. Suministrada regularmente por éstas, queda librada a la iniciativa del magistrado tan sólo en casos excepcionales... El convencimiento del magistrado depende, en el derecho vigente, en manera muy especial, de la actividad probatoria de las partes. Más que un método científico de investigación, la prueba civil se asemeja... a la prueba matemática: es una operación de verificación de la exactitud o el error de otra operación anterior" (33).

Creemos poder concluir con varias claras enseñanzas. Algo es justo o verdadero en el modo de conocer del proceso civil, cuando tal modo cumple ciertos requisitos establecidos en la ley, los cuales no tienen que ver, en primer lugar, con la realidad de lo que se conoce, sino con la validez del modo de conocer. EI modo de conocer que se establece en el sistema -bajo el principio dispositivo- es tan riguroso y predeterminado que no vemos cómo puede el juez realizar,

31 Ibídem.

32 Ibid., pág. 466. Anteriormente, Carnelutti, en sus Lizione di diritto processuale civile, V. III, pág. 246-47, trata este tema casi en el mismo senticlo que en su Prueba Civil, Cedam, Casa Editrice Dott, Antonio Milani. Padova 1933.

33 COUTURE, E., Fundamentos del derecho rocesal civil, Bs. As., Ed. Depalma, 1966, 3a. ed., pág. 218219. Leo Rosemberg en su Tratado de derecho procesal civil, Bs. As., Ed. EJEA, 1955, 5a. ed., p. 386, niega la contradicción entre verdad formal y material. El egoísmo de las partes en el proceso de base dispositivista también tiende al establecimiento de la verdad. 
efectivamente, su labor de "juzgar", ni cómo puede expresarse esa justicia como fuerza de espiritu de la que habla el mismo Carnelutti.

El sistema de Carnelutti como tal no es criticable, en el sentido que cumple su finalidad de sistema dentro de la funcionalidad de sus términos y postulados. El problema surge cuando disuena, en la vida misma de los litigantes, tal pretensión de cientificidad o matematización de la verdad de los hechos; y existe siempre el sentimiento de que no se realiza la justicia en el solo cumplimiento de las normas procesales. Una crítica en el orden mismo del fundamento último de estas ideas (derecho público, derecho privado) la hace Guasp, diciendo:

"las doctrinas liberales e individualistas, en efecto no podían por menos de llevar a cabo en el Derecho Procesal la supresión de manifestaciones de la actividad del Estado y la proclamación de los "derechos del particular" a conducir el proceso. Ello no era más que una expresión del sentido general de tales doctrinas, contrarias en un todo a la ingerencia estatal; una simple aplicación del "laissez faire, laissez passer: le monde va de lui meme. .."

..."cuando se dice que el juez no tiene la imparcialiclad suficiente para intervenir en el proceso, se teme la actividad del Estado; cuando se afirma que las partes son las que mejor pueden aportar los hechos de influencia, se desconfía asimismo del órgano del Poder Público" (34).

En este sentido, lo que llamamos principio dispositivo o inquisitivo no es tal "en sentido propio - de orden conceptual- sino criterios metódicos tendenciales" (35).

Por último, ya sea la aceptación franca de una tendencia dispositiva como defensa de derechos privados, o en la construcción sistemática, sobre esta base, del proceso civil, lo que se ha querido lograr es evitar la "arbitrariedad del juez" y en esta celosa lucha se ha caído en la arbitrariedad de las partes. Una expresión más de esta concepción del Proceso Civil es la que nos proporciona Carlo Furno en su "Teoría de la Prueba Legal". Aquí no se da un planteamiento siste-

34 GUASP, op. cit., pág. 129.

35 REDENTI, E., Derecho procesal civil, Bs. A., Ed. EJEA, 1957, t. 1, p. 261.

36 FURNO, Carlo, Teoría de la prueba legal, Madrid, Ed. Revista de Derecho Privado, 1954. mático como el de Carnelutti, pero tiene sus méritos propios: tratar de eliminar el término "verdad" y sustituirlo por "certeza", que expresaría mejor el fin del proceso civil. Pero la certeza de que aquí se habla es la convicción que "es la medida psicológica de la certeza" (37), y la certeza es la única posible de aceptar 'para la realidad de nuestro conocimiento' (38). Conforme a esto. hablar de certeza (o de representación subjetiva de la verdad histórica por el mecanismo de la convicción), constituye -lo creemos con Furno- "un progreso respecto a hablar, sin más e impropiamente de verdad" (39).

\section{La crítica de Furno a la verdad material y verdad formal}

Furno desde su planteamiento de la certeza elimina las discutidas posiciones de "verdad material" y "verdad formal". Según Furno, la verdad material responde a hechos pasados o que perduran en el presente y no puede identificarse con la "verdad absoluta (que es un ente ideal) ni con la certeza matemática" (40). y por otro lado la llamada verdad formal no es considerable como "un tertum genus" de certeza entre la verdad matemática y la histórica. Así es posible, desde este punto, eliminar por lo menos la terminologia de verdad material y verdad formal y con ella la ilusión de que se trata de dos situaciones contradictorias y que una de ellas está más cerca de la verdad. Según esto

"por verdad material se entiende la certeza histórica lograda en el proceso por vía de una o más experiencias probatorias, cuyos resultados deben ser apreciados por el juez con plena y absolutiz libertad de criterio, sea que las partes contendientes faciliten al juez todo el material instructorio preciso, sea que el mismo juez supla, con su propia iniciativa, las eventuales lagunas de instrucción procurándose él mismo las pruebas. En uno o en otro caso el elemento probatorio va siempre dirigido a formar la convicción del juez, con perfecta discrecionalidad para su valoración". (41). Y por verdad formal "se entiende la certeza histórica lograda en el proceso, no a través de la valoración crítica libremente ejercida so-

37 Ibid., pág. 18.

38 Ibid, pág. 19.

39 Ibid., pág. 22.

40 Ibid., pág. 24.

41 Ibid., pág. 25. 
bre el material probatorio por el órgano judicial, sino en virtud de un sistema legal de acertamiento definitivo de los hechos, o sea, en virtud de un complejo de normas imperativas, las cuales suprimiendo por completo la libertad judicial de valoración, vinculan al juzgador a tener por ciertos los hechos concretos, demostrados en los modos correspondientes a las hipótesis previstas en abstracto por aquellas normas. Aquí queda totalmente ensombrecida la íntima y autónoma persuasión del juez, sin que le reste otro quehacer que el de comprobar la exacta correspondencia del medio de acertamiento con la hipótesis legal y constatar la consiguiente fijación del hecho como definitivamente cierto" (42).

Con estos precisos significados la verdad material y la verdad formal pueden muy bien cambiar a otra terminologia más propia: certeza histórica judicial y certeza histórica legal, respectivamente.

Establecido esto, la supuesta contradicción desaparece y el problema de la verdad ya no es esencial sino respecto al modo de conocer. Con el segundo modo de conocer se ha logrado salvar una institución de derecho positivo que satisface, sin discusión, más allá de lo meramente procesal, una necesidad social y jurídica de "seguridad, equilibrio y estabilidad" (43).

Con esto Furno se centra en la más pura doctrina privadisía no sólo del proceso sino del derecho; se ha logrado una vez más insistir en lo que ya es un valor superior: seguridad. Para mantener en el proceso, tal "ideal" se hace necesario un camino a la verdad prefijado y asi el proceso "comienza a servir a la causa de la certidumbre antes e independientemente de que el proceso surja"' (44).

Esto determina que no es el juez el sujeto central y el que decide en última instancia el litigio, sino el legislador: "en la prueba legal el momento probatorio se presenta en la mente del legislador" (45). En este sentido Furno concluye afirmando que al legislador se le puede considerar "juez de jueces" (46).

Conforme hasta lo aquí expuesto, Furno determina dos sistemas de valoración de la prueba, un doble mo-

42 Ibid., pág. 25.

43 Ibid. pág. 27.

44 Ibid., pág. 28.

45 CHIOVENDA, Principii di d.p.c., Nápoles, 1928, $4 a$. ed., p. 311 , cit. por FURNO, op. cit.

46 Ibid., pág. 29 do de acertamiento de los hechos. La valoración estaria repartida entre el juez y el legislador, por lo tanto el juez debe aceptar y respetar "qué zona de su actividad de valoración está ocupada ya por la valoración formulada por el legislador" (47). Esta es la más clara manifestación del valor "seguridad" y, agregaríamos "previsión", que se desea del proceso civil. Está dada la posibilidad de que el litigio se convierta, como con frecuencia sucede, en una "carrera" legalista sobre la base de cualquier medio - pues no importa la "realidad" - para cumplir con la valoración previa.

\section{Certeza judicial y certeza legal}

Dentro del planteamiento de Furno es claro que no puede existir diferencia esencial entre "certeza histórica judicial" y "certeza histórica legal", pues son las dos maneras que se dan para el conocimiento de los hechos: la segunda es la convicción del juez y la primera la convicción del legislador, que es el juez de jueces, $y$, en este sentido, codetermina el convencimiento del juez (legal). Según esto, el fin del proceso no será "el logro de la certeza de los hechos objeto del pleito" (48). Afirmar esto es confundir el medio con el fin. Aún más, "en cierto aspecto, ni siquiera es rigurosamente exacto decir que la certeza histórica sea siempre indispensable" (49) (por ejemplo, según Furno, el caso de una sentencia que absuelva al demandado porque el actor no ha aportado la prueba de los hechos afirmados como base de su pretensión). La certeza histórica, pues, no se constituye como fin del proceso, sino como medio para alcanzar el fin que consiste en: "la tutela del derecho objetivo mediante la aplicación de la sanción". El proceso no se hace "para saber cómo han sucedido las cosas en la realidad, sino para saber cuál es la concreta voluntad legal que regula el caso concreto objeto del litigio" (50).

Una vez más se comprueba el exceso teórico de formalismo y de ficción. En esta posición el Estado no tiene más interés que el de ser un aplicador de la sanción para lograr la "pacificación jurídica".

El Estado es sólo un garantizador, conforme al derecho objetivo, del resultado del conflicto de los intereses privados. Según lo que interesa a las partes la

47 Ibid., pág. 29.

48 Ibid., pág. 33.

49 Ibid., pág. 33.

50 Ibid., pág. 35. 
intervención del Estado por medio de "la autoridad judicial, no tiene por qué conocer de la situación procesal de hecho sino en la parte que sea indispensable y suficiente para los fines de la decisión definitiva de fondo" (51). De esta forma el Estado sólo conoce lo "suficiente" para lograr una verdad suficiente.

La verdad suficiente, conforme con lo hasta aquí expuesto, es una "determinada cantidad de verdad". No interesa la verdad como problema del Derecho Procesal, ni por supuesto, como objeto de preocupación del juez. Lo que importa es qué cantidad de certeza hịstórica logra el juez en el litigio. Esta cantidad de certeza histórica está determinada por la ley y la actividad de las partes. De esta manera la verdad o certeza histórica se constituye como previsible.

Si Furno se mantuviera en esta coherencia no tendría necesidad de afirmar, sin especificar qué quiere decir con ello, lo siguiente: "que el juez se mantenga lo más imparcial y desinteresado posible frente a la controversia que se desarrolla ante él, respecto a la cual debe hallar, sobre todo en su conciencia, una serena directriz de justicia” (52). ¿Qué serena directriz de justicia puede tener el juez dentro de las limitaciones y categorias que se le imponen?. Ni siquiera debe mentarse la palabra "justicia”, pues decirlo, es justamente indicar el carácter abstracto e ideal de la actividad del juez respecto al hacer justicia, punto que Furno rechaza explícitamente. ¿Debemos pensar que Furno comprende que es imposible continuar el camino que él pretende?

Según la doctrina y la mayoría de códigos procesales civiles el problema de la verdad tiene su concreta exigencia en el deber de decir verdad. El planteamiento de Furno al respecto, se puede precisar en lo siguiente: "si hay algún sector del derecho en el que convenga pasar en silencio sobre el tema de la "moralidad", es, precisamente, el del proceso. En el fondo de cualquier pleito hay siempre un vicio (unilateral o bilateral, grave o leve) de moralidad", la moralidad en las relaciones jurídicas "induce a guiñar el ojo y a tratar a todos los litigantes con un mismo criterio apriorístico desde el punto de vista de la buena fe" (53). Es, pues, claro que la obligación de decir verdad que se manifiesta como moralidad o buena fe no es asunto del proceso.

51 Ibid., pág. 47.

52 Ibid., pág. 51 .

53 Ibid., pág. 54.
Si por un lado no se trata de ningún problema "cualitativo" de la verdad en el proceso civil, y por otro las partes, en general, tampoco obran conforme a la verdad entonces es posible afirmar, como lo hace Furno, "déjese a las partes que digan impunemente, si lo desean, sus constantes mentiras, y déjese que el juez las escuche con intención recelosa. .." (54).

Si por debajo de la pretendida "teoria" sobre el proceso civil dispositivo se esconde este fundamento, no vemos cómo es posible tomar teóricamente en serio que "una mentira inhábil ilumina a menudo la conciencia del juez prudente con una luz de certidumbre", lo que hace suponer que una mentira hábil engañará aun al juez prudente y entonces es falso decir, como lo hace Furno, que "no será posible jamás que una mentira detenga el curso de la justicia" (55).

La correcta conclusión de esta doctrina es que el fenómeno jurídico no es nunca ni moral ni inmoral, y no lo es porque se "quiere" que esto sea asi. En otras palabras, como ya lo anota Friedrich (56), esta posición sirve extraordinariamente bien a la actuación apasionada e interesada de los hombres, es la posibilidad legal del egoísmo y las malas artes para conseguir una "seguridad" pronta y "económica".

II

\section{EL PRINCIPIO INQUISITORIO}

\section{Su función}

El planteamiento del proceso civil, contrario a la doctrina expuesta, es el de tendencia inquisitoria - para ya no decir principio-. En esta tendencia va implícita una concepción diferente tanto del estado como del derecho en general, y por ende, del proceso civil. Esta tendencia tiene como base la primacia del interés público, representado por el juez, sobre el interés particular; y por esta vía se le restablece plenamente al juez la dignidad de la dirección del proceso, la facultad de apreciación de los hechos y de la investigación de la verdad material. (57)

Hay que distinguir dos planteamientos diferentes dentro de la tendencia inquisitoria:

54 Ibid., pág. 55.

55 Ibid., pág. 55.

56 Ibid., pág. 281.

57 ALZAMORA V., Mario, Derecho procesal civil, teoría general del proceso, Lima, 1959, pág. 168. 
1. El primero plantea que el proceso es de interés público en general y que por esto el juez tiene la obligación de hacer cumplir el interés del Estado logrando la verdad real y por ello la justa sentencia.

Conforme a esto la tendencia inquisitoria es llamada también de "oficialidad" o de "investigación" y "faculta al juez a averiguar de oficio la verdad material o absoluta de los hechos sujetos a controversia. Su fundamento radica en la idea directriz, de que por encima del interés particular está el interés social" (58)

Las partes, sin embargo, continúan aportando las pruebas (carga de la prueba), pero le toca al juez investigar si las "pruebas son reales" (59). En este sent:do, el proceso civil. se convierte en "una función del Estado", como dice Couture. Aunque nos parece prejuiciada la observación de Couture cuando expresa: "Siendo así, puede afirmarse que la condición que se hallan entre sí las partes y el juez, representando en pequeño, la posición en que se hallan, en su medio, las ciudades y el poder; las partes actúan en el juicio en una expresión particular del sistema vigente en las relaciones entre el hombre y el Estado; entre la libertad y la autoridad" (60). Esta definición es la que más se emplea para argumentar en contra de esta tendencia. Al proceso inquisitorio, en este sentido general que involucra una concepción del Derecho y del Estado, se le asocia a los regímenes totalitarios llegando a pretender encontrar su razón de ser en ellos. Así, por ejemplo, el Proyecto Preliminar del Código

58 PEZO V., "El principio inquisitivo en la reforma del proceso civil" Rev. Jurídica del Perú, Año X, Lima, 1959, pág. 227. Esto exige, como bien lo observa Valdivia Pezo, en el elemento humano, es decir el juez, "la prevalencia de las fuerzas morales y los atributos del intelecto, en mayor medida que hoy". Es decir una rigurosa selección y formación de jueces. Este es tema de nuestro trabajo en preparación Fuentes para un sistema judicial peruano.

59 Ibid., pág. 231.

60 COUTURE, E., "Direcciones políticas del derecho procesal contemporáneo" en Cultura Jurídica, año I, Enero-Marzo, No 1, Caracas, 1941, pág. 9. Allorio reconoce la publicización del derecho procesal como fórmula de su historia típica "en la fórmula de la publicización del derecho procesal o sea, mutación gradual de ese derecho, de una primitiva figura individualista a una final organización según el principio autoritario", Allorio, op. cit., t. I, pág. 210. de Procedimientos Civiles del Ministro Salmi de Italia de 1937 expone, entre otros puntos, los siguientes:

a) "El proceso no sirve a la satisfacción de intereses particulares sino al aseguramiento de fines públicos. El proceso sirve a las partes, pero sirve, sobre todo, a la tutela de un altísimo interés público, que es esencial a la vida del Estado Fascista, el cual, tanto en las relaciones sociales como en las relaciones jurídicas, quiere ser un Estado de Justicia.

b) “...La moralización del proceso; es decir el escrúpulo de la verdad y el ansia de que el proceso no sea un instrumento de acción injusta sino un verdadero receptáculo de sincerida, de probidad y de verdad" (61).

Otro ejemplo, dentro del mismo sentido, se da en la exposición de motivos del Código de Procedimientos Civiles del Brasil por el entonces Ministro Francisco Campos, quien dice:

"la dirección del proceso debe caber al juez; a éste no le compete sólo un papel de velar por la abservancia formal de las reglas procesales por parte de los litigantes. El juez debe intervenir en el proceso de manera que logre, por los medios adecuados, el objetivo de investigación de los hechos y descubra la verdad" (62).

$Y$ por último,en este mismo sentido se expresa la Exposición de Motivos del Código Federal de Procedimientos Civiles de México:

"Debe otorgarse la más amplia libertad a los juzgadores para recabar las pruebas que estimen necesarias, para el dictado de un fallo acorde con las relaciones jurídicas que ligan a las partes fuera del proceso, y no con una falsa y parcial apariencia de esa realidad, como puede resultar de los autos, por malicia o torpeza de los litigantes".

No podemos olvidar que los tres ejemplos citados no hacen referencia alguna a una "autoridad" o "prepotencia estatal"; en virtud de la autoridad no se investiga la verdad, es justamente en virtud de la verdad misma que debe imperar en el comportamiento de las partes. Según esto el juez logra la convicción necesaria para dictar sentencia. Alcántara observa: "el

61 Cit. por COUTURE, Direcciones politicas...

62 Cit. por MACHADO GUIMARAES, "Proceso autoritario e regime liberal”, en Rev. Forense, Vol. LXXXII, 2do. Trim., Río de Janeiro, 1940, p. 243. 
principio inquisitivo tiene su fundamento propio, el derecho del juez a la verdad, y no necesita ampararse en criterios de autoridad para aumentar los poderes del juez" (63). La actividad "ex-oficio" del juez no implica, en este nivel, el anulamiento de la actividad de las partes. Partes y juez colaboran realmente a la realización de su finalidad última: dar la justicia a quien la tenga sobre la base de la verdad. Por esto es correcto afirmar: Nadie podrá ver mal que un juez aspire a conocer la verdad y haga lo necesario para conseguirlo. Mucho más que las habilidades de una parte y los descuidos de otra, interesa el imperio de la verdad y el triunfo de la justicia.

2. El segundo planteamiento de tendencia inquisitoria propone que esta se lleve a cabo cuando

"se trata de materias que afectan al orden público, y especialmente las referidas al estado civil o condición de las personas y a la familia, no cabe que las partes puedan disponer del objeto ligioso, y ni siquiera de la oportunidad $y$ conveniencia del proceso. De aquí que, lógicamente, debicra ampliarse el ámbito de las facultades directivas del juez, ya que dichos procesos deben estar regidos por el principio de la oficialidad y de inquisición de oficio” (64).

Goldschm:dt, en 1953, hablaba de idealización del principio inquisitorio, expresando que "se idealiza diciendo que constituye la expresión de un fuerte poder estatal trasladado al tribunal y da un impulso inquebrantable hacia la verdad, que se independiza de la voluntad de las partes" (65). Goldschmidt cree que el fin del proceso no es la verdad real sino "establecer la paz jurídica entre las partes”. Nuevamente, en esta critica de Goldschmidt, se relacionan la autoridad,

63 ALCANTARA S., "Intervención de oficio en el proceso civil", Rev. de Derecho Judicial, Año III, N 9 , Madrid, 1962, p. 15.

64 CANERAS LLAUSANA J., "La función del juez en la dirección del proceso civil", Rev. del Instituto de Derecho Comparado, $\mathrm{N}^{9}$ 19, jul-dic., Barcelona, 1962, p. 87.

65 GOLDSCHMIDT R., "Las funciones del juez dentro del proceso civil en el momento histórico actual", Ponencia presentada al Congreso Internacional de Derecho Procesal Civil, Viena, Oct. 1953. En Rev. de Col. de Abogados del Distrito Federal, Año XVIII, Set-Oct., No 83, Caracas, 1953-54, p. 103. el interés público y el poder estatal con la idea de investigar la verdad.

Según, y admitiendo la división entre interés público $y$ privado en el proceso, podemos afirmar que la tendencia inquisitoria dispone de más amplios criterios para que el juez no se atenga sólo a la observación del cumplimiento de las normas procesales por las partes.

Un sistema, sobre la base de la tendencia inquisitoria, no ha sido desarrollado; sin embargo su adopción originó acuciosos comentarios. El Código de Procedimiento Civiles de 1940, que rigió desde 1942 en Italia, fue motivo de tales comentarios, no obstante que no acoge plenamente la tendencia inquisitoria, como sí lo hacía el Código de la Italia Fascista. Carnelutti diría al respecto: "En general, se han ampliado los poderes del juzgador por lo que atañe a la dirección del proceso y el acertamiento de la verdad de los hechos" (66). Según Cernelutti se da, en el Código, la división que anotamos: la tendencia inquisitoria en los casos de materias no disponibles por los particulares, y esto es debido "a la influencia cada vez mayor del derecho público sobre el derecho privado", y agrega, "hasta convertirse en excesiva, insoportable y perturbadora, muchas veces".

En "El proceso inquisitorio en el nuevo Código Civil" Carnelutti observa dos axiomas que deben guiar toda reforma procesal:

1. "Que todo desplazamiento que se verifique en el derecho sustancial, del punto de encuentro entre interés público e interés privado, lleva indefectiblemente y sin necesidad de una explícita reforma de las leyes procesales, a dar, en correspondencia, un diverso equilibrio a las fuerzas motrices del proceso".

2. "Que toda reforma procesal con la cual se trate de dar un diverso orden a las relaciones entre la actividad del juez y la actividad de las partes corre el riesgo, si no se hace en armonía con el derecho sustancial, de reaccionar sobre éste de un modo imprevisto, hasta el punto de constituir una reforma indirecta del derecho sustancial, efectuada impensadamente a través del proceso" (67).

66 CARNELUTTI, op. cit., t. I, p. 414.

67 CARNELUTTI F., "El proceso inquisitorio en el nuevo Código civil", en Estudios sobre el proceso civil, Bs. As., Edit. Bibliográfica Argentina, 1945, p. 352. 
La contraposición entre el proceso civil dispositivista e inquisitorio se da conforme al segundo axioma $y$, respecto a éste, la distinción fundamental se da "en la diversidad de sujeto al cual están confiadas las palancas de mando que sirven para regularlo" (68). Esto responde, según el primer axioma, a una "distinción más vasta y general... entre derecho público y derecho privado". Carnelutti reconoce que "todos los intereses protegidos por normas jurídicas, aun cuando sean individuales" interesan al Estado y por ello las protege, pero el Estado sienie con mayor o menor intensidad tales derechos. La intensidad de ellos determina el cuidado: privado o público. Desde este punto de vista se puede hablar de dos tipos de procesos "el proceso de tipo dispositivo, para las controversias de derecho privado súricto sensu. y el proceso de tipo inquisitorio para las controversias sobre derechos indisponibles" (69). Lo que propone Carnelutti es que si se quiere mantener el proceso inquisitorio se debe crear un título dentro del Código de Procedimientos Civiles llamado proceso sobre relaciones indisponibles. Entonces, "el proceso inquisitorio sería, un instituto elástico, adaptable a todas las controversias cuya naturaleza susiancial no fuese conciliable con el predominio de la iniciativa privada. que es propia del proceso de tipo dispositivo..." No obstante esto, Carnelutti reconoce que cada dia el derecho subjetivo se esf́uma y "la responsabilidad privada se disuelve bajo la ingerencia de la autoridad" (70).

La critica de Carnelutti nos hace ver una vez más las bases, nada autćnomas, sobre las que se desarroIlan las tendencias procesales civiles. En el mismo sentido se expresa Calamandrei en un artículo escrito originalmente en 1927. Pero quiere restarle importancia al derecho público, cuyo auge sería causa de aceptación del proceso inquisitorio, y también la "naturaleza publicista de la relación sustancial sometida a decisión" (71). La aceptación del proceso inquisitorio, según $\mathrm{Ca}$ lamandrei, responde a un tipo especial de interés público. A la pregunta ¿en qué consiste la naturaleza especial de las relaciones del derecho sustancial que son

68 Ibid., pág. 353.

69 Ibid., pág. 356.

70 Ibid., pág. 362.

71 CALAMANDREI, Piero, "Líneas fundamentales del proceso civil inquisitorio", en Estudios de derecho procesal civil, Bs. As., Edit. Bibliográfica Argentina, 1945 , p. 237. objeto del proceso civil inquisitorio?" (72), Calamandrei responde que "la relación sometida a decisión sea tal que el Estado tenga interés en no permitir su modificación sino a través de una declaración jurisdiccional de certeza" (73). Según esto el tipo de interés "se puede configurar más bien como el interés del Estado en la exclusión de cualquier composición del conflicto que no sea realizada mediante sentencia".

La calificación de proceso civil inquisitorio se debe entender, entonces, en el "sentido de un proceso de partes, en el que predomina el principio inquisitorio, esto es, en el que el juez, teniendo ante si las dos partes, esté vinculado, para la investigación de la verdad, de la iniciativa y de los acuerdos de las mismas" (74). La "investigación de la verdad", dentro del contexto de Calamandrei, no es ninguna esperanza en el sentido de "investigar la verdad real"; la investigación de la verdad siempre se realiza dentro de los cánones del proceso dispositivo. Lo que quiere conseguir Calamandre:, concientemente $o$ no, es una coexistencia del proceso dispositivo e inquisitivo, como él mismo lo dice:

"En suma, el Estado en los procesos en que se trata de decidir sobre la validez de una relación jurídica concerniente al Estado y a la capacidad de las personas, se emplea regis ut veleat quam ut pereat, y por eso se contenta con el principio dispositivo ut veleat, pero hace del principio inquisitorio una condición indispensable ut pereat", (75) y concluye, "el proceso cicil inquisitorio está construido para servir del mejor modo posible a este fin fundamental: garantizar que la actividad administrativa necesaria para modificar ciertas relaciones de derecho privado, que es socialmente útil mantener $\sin$ variación mientras falten los presupuestos de modificabilidad o de anulabilidad rigurosamente previstos por la ley, no pueda ser prestada por el Estado sino en virtud de pronun-

72 Ibídem. Por eso "En realidad, estamos todavía, probablemente, por lo menos para el proceso civil, lejanos de semejante estadio extremo" y por ello hay que reconocer que "sólo en la atmósfera del liberalismo puede florecer el proceso". Véase Allorio, E., Problemas de derecho procesal, Bs. As., EJEA, 1963, t. I, p. 167.

73 CALAMANDREI, op. cit.. p. 237.

74 Ibid., pág. 251.

75 Ibid., pág. 260. 
ciamiento jurisdiccional que declare la existencia de tales presupuestos" (76).

En 1943, un año después de haber entrado en vigencia el C.P.C. Italiano, Calamandrei escribe, en su "Instituciones de Derecho Procesal Civil", remarcando el mantenimiento del nuevo código dentro de la tradición dispositivista, lo siguiente: “. . el poder de suposición de las partes se manifiesta en señalar los límites del thema probandum, pero, dentro de estos límites, el reconocer al mismo juez que debe indagar sobre la verdad de los hechos alegados por las partes una cierta autonomía en la elección de los métodos de investigación, aparece como una necesidad de orden técnico, que no tiene nada que ver con el respeto a la voluntad de las partes" (77). Es claro que la investigación de la verdad, dentro de estos términos, no permitirá traer al proceso, por el juez, hechos "verdaderos" que influencien en el proceso, que no estén dentro del thema probandum fijado por las partes.

Expresa lo mismo con respecto a la aceptación del principio inquisitorio. Se le acepta sólo en lo referente a las llamadas relaciones indisponibles o "atinentes al orden público" en las cuales el juez aumenta en poderes.

La moralización, en función de la verdad, que se proponía en 1937 por el Ministro Solmi es ahora recogida en su "justo medio" como dice Calamandrei. La relación del Ministro Grandi, del C. P. C. de 1940 dirá:

"los litigantes se darán cuenta de que el engano no sólo no servirá para vencer las causas sino que podrá con frecuencia servir para hacerlas perder, y se sentirán impulsados a comportarse según la buena fe, no sólo para obedecer a su conciencia moral, sino también para seguir su interés práctico, el cual les advertirá que, a fin de cuentas, la falta de honestidad no constituye nunca, ni siquiera en los procesos, un buen negocio" $(78)$

76 Ibid., pág. 261.

77 CALAMANDREI, P., Instituciones de derecho procesal civil, Bs. As., Edit. EJEA, 1962, Traducción de la 2a. ed. actualizada de Instituzioni di Diritto Processuale Civile secondo il nuovo Codice, CEDAM, casa editrice Dott Antonio Milani, Padova, 1943, p. 406-407. No es claro a qué orden técnico se refiere ni en qué sentido.

78 Relación Grandi, cit. por CALAMANDREI, op. cit., pág. 416.

\section{Critica a la facultad inquisitoria del juez}

Es común encontrar en la literatura procesal civil, como argumento para descartar la facultad inquisidora del juez, el conflicto sicológico que se produce entre juzgar hechos aportados por las partes y la de incluir hechos que las partes no han usado en el thema probandum. Se argumenta que si el juez llevara al fallo conocimientos particulares "no cabe después un nuevo juicio sobre la certeza e idoneidad de tales conocimientos" (79). Esto no es correcto, pues "por el contrario, cuando el juez en un proceso tuviese noticia de la existencia de algún hecho relevante para el mismo y que las partes no hubieran utilizado, su actitud debería ser la de aportarlo al material de decisión y dejar constancia objetiva de él, lo mismo que la de cualquier hecho alegado por las partes. Esta constancia objetiva permitiría, igual que en las restantes hipótesis de operaciones probatorias la revisión ulterior de la certeza de tales circunstancias" (80). La clandestinidad de hechos está, en este sentido obstaculizada, y no asi en cambio en el proceso dispositivo.

Por otro lado es bastante curioso que sólo se haga notar una parte de la cuestión, pues el mismo conflicto sicológico se produciría en el juez al juzgar hechos que él sabe falsos. En realidad lo que se pretende evitar, con esta crítica, es que el juez sea "incapaz de criticar y juzgar la realidad material de las circunstancias que le son sometidas" (81). Lo que se busca con el principio inquisitorio no es sustituir a las partes en la aportación de los hechos, ni dar un camino abierto al juez para consagrar su arbitrariedad, sino que, si se debe hablar y creer en la verdad o justicia como valores jurídicos, entonces no es posible "legitimar" la inminente probabilidad de la mentira y falsedad que permite el proceso dispositivista. La tendencia inquisitoria con su nota fundamental de "derecho público" ha permitido que el proceso civil sea considerado no ya "como expresión de una lucha de intereses privados, sino como instrumento de la más augusta entre las funciones del Estado" (82). Tal situación ha vuelto a tocar los cimientos morales de los hombres, y especialmente, de las partes y el juez. Por esto di-

79 GUASP, op. cit, pág. 90.

80 Ibídem.

81 Op. cit., pág. 92.

82 CALAMANDREI, P., "El nuevo proceso civil y la ciencia jurídica”, en Los estudios de derecho procesal civil en Italia, Bs. As., Edit. EJEA, 1959, pág. 73. 
ce Calamandrei, recordando la parte final de la relación del Ministro Grandi: "el éxito de la reforma se plantea sobre todo como un problema de hombres..." (83).

En este sentido, pues, el proceso inquisitorio se plantea como esencialmente opuesto al proceso dispositivo.

\section{Determinación de las facultades del juez}

Se ha dejado más o menos establecido que el proceso inquisitorio desea dejar abierta la posibilidad, sobre los fundamentos ya expuestos, de que el proceso se realice, no para la egoísta actividad de las partes que permite el ocultamiento, sino para el establecimiento de la verdad de los hechos en litigio.

Según esto, el juez tiene un campo de conocimiento más claro y preciso que determinará una sentencia arreglada a la realidad. En este sentido, las normas procesales no prefijan la verdad o falsedad de las pruebas aportadas por las partes en la sola virtud de cumplir los requisitos legales, sino que las normas indicarán el camino a seguir, pero no su validez, de verdad o falsedad. Ellas, la verdad o falsedad siempre se fijarían por la correspondencia de las afirmaciones de las partes con el hecho histórico. Una inmediata consecuencia de esta tendencia es la rectitud del comportamiento de las partes en litigio y la posibilidad de que dichas conductas se ordenen de acuerdo a los cánones

83 Ibid., pág. 85. Recobrar para el derecho público el proceso civil ha permitido que se recuerde nuevamente los extremos del formalismo legal en el que se ampara el proceso dispositivo. Es oportuno citar a Zitelmann:

"Si el jurista y- primero el juez- olvida la magnitud y amplitud de su misión -y la olvidará harto fácilmente si sólo se nutre en su profesión de los textos de la ley- si cree que le basta la elaboración de estos textos para cumplir sus deberes, la jurisprudencia degenerará en oficio de "rábulas" y "leguleyos", con pedantería y sofistería: como sólo operará con razones lógicas, no encontrará eco alguno en el ánimo de los postulantes: éstos se verán desamparados en la lucha por intereses en los que acaso les va la vida, y a merced de un poder para ellos enigmático; y así se irá abriendo un abismo cada vez más hondo entre el derecho de los juristas y la conciencia del pueblo".

Die Gefahren des BGB fur die Rechtswissenschaft, 1896, págs. 17-18, cit. por Guasp, op. cit., pág. 107. éticos (deber de decir verdad). El Estado se erige, entonces, en el guardián, por medio del juez, de tales normas y de la conducta de las partes, no ya para implantar su autoridad sino para que se cumpla un determinado ordenamiento.

Con respecto entonces a los hechos se puede decir:

a) Los hechos que limitan la pretensión de las partes son proporcionados por ellas.

b) Los hechos que completan o aclaran lo pretendido por las partes pueden ser proporcionados por el juez.

c) También es permisible que el juez actúe con respecto a los hechos que sirven de prueba, en el sentido de dejar constancia objetiva de la correspondencia con la realidad.

Según Guasp la investigación de la verdad por el juez no debe configurarse como un "deber" que obliga a una forzosidad de cumplimiento, sino, como una facultad que puede o no realizarse. Conforme a esto ya no es posible aceptar la tan manida observación de los procesalistas defensores del dispositivismo: "decaería el estímulo de las partes que hoy las mueve" (84).

De otro lado debe dársele más importancia a la natural regla reguladora dentro del proceso: la fundamentación de la sentencia. Los dispositivistas olvidan tal situación, pues cualquier libertad que se le deje al juez dentro de un proceso inquisitorio debe reflejar su seria actividad de juez, investigador de la verdad, en la fundamentación de la sentencia. Abrir el proceso civil a la inquisición de la verdad de los hechos es insistir una vez más en lo ya observado por el Ministro Solmi y por Grandi en las sendas exposiciones de motivos de los Códigos de Procedimientos Civiles de 1937 y 1940, es decir, que la responsabilidad del proceso recae plenamente en los hombres: juez y partes.

La exposición del proceso civil dispositivista y del inquisitorio nos hace apreciar nuevamente que la base de dichos procesos es política y responde a criterios no provenientes de la misma actividad procesal. Cambiada la tendencia se cambiará el objeto y el fin del proceso; en tal situación no es posible hablar de una "ciencia procesal civil". Por eso es necesario encontrar un camino, proponer un "método" que permita una construcción pura del proceso del conocimiento de los hechos en el proceso civil.

84 GUASP, op. cit., pág. 121. 
Tanto el proceso civil dispositivo como el inquisitorio encuentran, pues, su última razón en la conocida y no cierta -en el sentido y la perennidad que se le ha utilizado- división del derecho en público y privado. La referencia que se hace para justificar históricamente tal división es la expuesta por Justiniano en sus Instituciones y por Ulpiano en el Digesto. (85) Pero se olvida relacionar estas citas con los preceptos del derecho que establecen: Vivir honestamente, no dañar a nadie y dar a cada uno 10 suyo. Lo interesante es mostrar que a través de la historia se ha unido a la famosa división del Derecho el "honestoe vivere" que era un 'precepto' del Derecho. Asi a la división de cosas y situaciones en privadas y públicas correspondian

"Este estudio tiene dos puntos: cl derecho público y el derecho privac!o. Se llama derecho público al que trata del gobierno de los romanos, y privado ol que se refiere a la utilidad de los particulares. Tratamos, pues, el derecho privado, que consta de tres partes: de los preceptos del derecho natural, del derecho de gentes y del derecho civil". JUSTINIANO, Instituciones, México, Ed. Bilingüe El Atalaya, 1947, Lib. I, Tit. 1,4. Del Derecho Natural dice, "... este derecho no es especial del lina e humano, sino común a todos los animales gre nacen en el cielo, en la tierra y en el mar. Lib. I, Tít. II). Derecho de Gentes: “... el que una razón natural establece entre todos los hombres, y se oloserva en casi todos los pueblos, se llama derecho de gentes, es decir, de todas las naciones", Ihídem. Derecho Civil: "es el derecho que cada pueblo se da excluivamente, es propio de los individuos de la ciudad, y se llama derecho civil". Ibídem. Esta división äpenas aparece formulada en las fuentes juricicas extrajustinianeas, Alvarez Sú́rez, op. cit., pág. 206.

"Dos son los aspectos de este estudio: el público y el privado. El derecho público es el que se refiere al estado de la cosa romana; el privado el que a la utilidad de cada individuo; pues unas cosas son útiles públicamente, y otras privadamente. El derecho público consiste en las cosas sagradas, las de los sacerdotes y las de los magistrados. El derecho privado consta de tres partes, pues está compusto de los preceptos naturales, o de las gentes, o de los civiles". ULPIANO, Digesto, Lib. I, Tít. I, Ley I, inc. 2. El texto de Ulpiano ha sido puesto en duda por Dulckeit en 1935, ver D’Ors Pérez Peix, Alvaro, Presupuestos críticos pa ra el estudio del derecho romano, C.S. de Investigaciones Científicas, Salamanca, 1943, pág. 17. también 'conductas privadas' y 'públicas'. Esta división se ha ligado al concepto de autoridad del juez $y$, por extensión, se ha llevado a considerar que en un proceso dispositivo de base privada, la autoridad del juez -como representante del Estado, sociedad, etc.- debe estar limitada en el conoc:miento de los hechos; y en cambio, en el proceso civil inquisitorio la autoridad del juez debe ampliarse en el conocimiento de los mismos. (86)

Ahora es posible comprender cómo toda una época doctrinaria l:beral, amparándose en esta relación, organizó el Derecho Procesal Civil predominantemente dispositivista. Esta posición se adoptó en casi todas las legislaciones positivas. El ant:guo Febrero Novísimo define al juicio civil como aquél en el cual "se ventila únicamente el interés particular" (87). Esta división interpretada en el sentido señalado sirve excepcionalmente bien para configurar el Estado y el derecho liberal y con ello para limitar la acción del Estado (derecho público) respecto del derecho privado. Lo público es mirado entonces como el gran fiscalizador, el gran ojo que todo lo ve y sanciona; en cambio to privado (interés privado), en sus inicios se hablaba de "libertad" privada, degenera después en el sentido de la voluntad libre de las personas, 0 de las partes en el proceso. El contrato, el acuerdo de voluntades constituye la ley entre las partes y lo que ellas fijen tiene que ser respetado. Una esiructura del proceso civil -como prolongación de la del derecho civil- debia responder a esta liberalísima actitud de las partes. La voluntad, ley entre ellas, debia prolongarse aun en sus liâigios en donde el juez no puede ejercer su autoridad más allá, ni en contra de las partes (88).

86 No olvidemos que "donde la influencia del Derecho Privado con el público se muestra, sin embargo, más precisa y coherente, es en lo relativo al procedimiento judicial". ALVAREZ SUAREZ, Ursicino, Horizonte actual del derecho romano, Madrid, Consejo Superior de Investigaciones Científicas, Instituto Francisco de Vitoria, 1944, pág. 63.

87 DE TAPIA, Eugenio, Febrero Novísimo o Librería de Jueces, Abogados y Escribanos, refunclida y ordenada bajo nuevo método y adicionada con un Tratado del Juicio Criminal, y algunos otros. Valencia, Imprenta de don Idelfonso Mompié de Monteagudo, 3a. edición, T. IV, 1837, pág. 82.

88 "Sociológicamente el contrato es la categoria fundamental de la vida burguesa entera, y la forma adecuada al tipo de unión llamado "sociedad" (como asociación), consistente en que sus miembros no es- 
En la ley, como voluntad de las partes, hay que entender que está inserta la verdad que ellas quieren revelar (de allí que sean posibles los procesos simulados). Esta situación originó que la conducta jurídica en litigio, sea diferente a la conducta moral (honestidad) fuera del litigio, así todo deber moral exige que la voluntad de las partes no interfiera con la verdad real de las mismas. El hecho que se considere en algunas legislaciones procesales civiles un precepto como el "deber de decir verdad" es sólo un débil destello en contra de la posibilidad legal de la mentira en el proceso civil dispositivo. La función privada del proceso civil, en la doctrina, se considera entonces como "el instrumento idóneo para obtener la satisfacción de un interés legítimo por acto de la autoridad" (89). En el mismo sentido se expresará Chiovenda al afirmar que el fin del proceso es "la actuación de la voluntad concreta de la ley, en relación a un bien de la vida que el actor pretende, garantizado por esa voluntad" (90).

La posición contraria que otorga al juez un status más digno y notorio en la dirección del proceso e investigación de la verdad, es el proceso civil en el que domina el carácter público. Nuevamente, como en la posición anterior, se recurre a la base politica para restablecer al juez las facultades antedichas y se coloca en el centro el "interés público" prevaleciente sobre el "interés privado". En este sentido en 1852 Böcking afirma el proceso civil "como lo que se abre al derecho público" (91). Consideramos ésta una feliz expresión para entender que las conductas en el litigio "se abren" a la visión del juez. En 1868, Bülow, considerado como el iniciador del proceso civil con base científica, dirá respecto del proceso civil:

"Se acostumbra hablar tan sólo, de relaciones de derecho privado. A éstas, sin embargo, no puede ser referido el proceso. Descle que los derechos

tán vinculados por lazos orgánicos, sino puramente voluntarios y racional-utilitarios; y esa forma de unión social es la que da el tono a toda la organización político-social del liberalismo individualista. . cuya forma política de organización es el Estado liberal de Derecho",

LEGAZ LACAMBRA, L, Filosofia del Derecho, Bosch, 2a. edición revisada y aumentada, 1961, pág. 482-483.

89 COUTURE, op. cit., pág. 146.

90 CHIOVENDA, Instituciones de derecho procesal civil, Madrid, 1948, pág. 40.

91 Cit. por O. V. BULOW, op. cit., pág. 2. y las obligaciones procesales se dan entre los funcionarios del Estado y los ciudadanos, desde que se trata en el proceso de la función de los oficiales públicos y desde que, también, a las partes se las toma en cuenta únicamente en el aspecto de su vinculación y cooperación con la actividad judicial, esa relación pertenece, con toda evidencia, al derecho público y el proceso resulta, por lo tanto una relación jurídica pública”(92).

Modernamente Raimundin hace resaltar este carácter público del procesó civil:

"Esta concepción individualista del proceso, ha sido abandonada por la doctrina procesal moderna; hoy se afirma entre nosotros, que el proceso es una figura del derecho público; ya no se admite que el proceso pueda ser una institución de derecho privado, sino por el contiario se conoce que es una relación del derecho píblico, que se establece entre las partes y el Estacio, cuyo objeto es obtener la actividad jurisdiccional, es decir proponer un fin píblico como es ha conservación de la paz y el orden público...", y refirićndose a la ley argentina 14237 ane consolida esta dirección del proceso civil, expresa, "la orientación del nuevo ordenamiento jurídico nos ha colocado frente a un problema central: la relación entre el individuo y el Lstado, es decir, la posición que han de tener las partes en la sustanciación del proceso y el ámbito de los poderes que han de acordar al juez. Al afirmarse el Derecho Procesal Civil en el dominio del Derecho Público, el Juez, de simpie espectudor se transforma en un sijeto activo del proceso.. basta señalar un esquema del principio de antoridad, el juez puede, en cualquie: estado dei proceso, disponer do medidas necesarias para esclarecer la verdad de los hechos" (93).

El aumento de facultades le permite al juez llegar a la verdad objetiva, evitar la mala fe y la negligencia de las partes, logrando con ello una sentencia más justa en tanto se acerca a la verdad de los hechos. Pero además la concepción del proceso dispositivo responde a la "filosofía del derecho formalista neokantiana" - $-y$ de aqui que la teoría pura del Derecho sirva excepcionalmente bien para fundamentar esta posición- tal filosofía

"ha negado, como era de esperar, esa posición especial del juez. Para ella el detinatario de

92 Ibídem.

93 RAIMUNDIN, R., Derecho procesal civil, Bs. As., Ed. Viracocha, 1956, pág. 89. 
la norma y ejecutor de ella como cualquier otro funcionario y como cualquier otro miembro de la comunidad jurídica. Pero en esa actitud se manifiesta simplemente otra vez la inquietante nivelación de todas las relaciones jurídicas a que da lugar esa consideración formalista que elimina como irrelevantes todos los momentos materiales de contenido" (94).

El problema se agrava cuando el 'contenido' tiene que ver con situaciones que revierten sobre la vida social y económica de las personas en litigio y de la misma comunidad. La evidencia del fundamento del proceso civil dispositivo se muestra ahora como tema de principalísima importancia, que inusitadamente llevará a todo el que piense en esto a replantearse su propia concepción del Derecho y del Estado y con ello su idea del juez.

Una concepción privadista, positivista, del Derecho y por to tanto del proceso incurriria en

"creer que pueda existir un derecho, en general, flotando, por decirlo así, sobre las cosas, independiente de los intereses políticos económicos. Cabe representarse un derecho semejante; y los hombres que toman por actividad política la que consiste en imaginar posibilidades políticas, se han representado así siempre el derecho. Pero esto no altera en nada la realidad; y la realidad es que un derecho semejante, un derecho de origen abstracto, no se presenta nunca en la realidad histórica. Todo derecho encierra en forma reducida la imagen de su creador, y toda imagen historica contiene una tendencia políticoeconómica, que no depende de tales o cuales ideas teóricas, sino de la voluntad práctica de la clase que tiene en sus manos el poder efectivo $y$, por lo tanto que crea el derecho. Todo derecho ha sido siempre creado por una sola clase social en nombre de la generalidad" (95).

Nuestra herencia directa del Derecho Romano como "un mundo helado de máximas y reglas abstractas, un aparato admirable por su solidez, seguridad de acción y fuerza, pero que no era más que una máquina" (96),

94 GOING, Helmut, Fundamentos de filosofía del derecho, Barcelona, Ed. Ariel, 1961, pág. 251.

95 SPENGLER, Oswald, La decadencia de occidente, Madrid, Ed. Espasa-Calpe, t. II, 1958. pág. 80.

96 VON IHERING, R., El espíritu del derecho romano, 2a. edición, Rev. de Occiclente, 1962, pág. 127.

"El derecho romano ha dejado de ser para nosotros el origen de los conceptos fundamentales, de unida a la moderna concepción formalista, hizo olvidar que

"El pensamiento jurídico necesita referirse a algo. Pero la fatalidad fue que, en vez de abstraer Ins conceptos de las fuertes y precisas costumbres de la existencia social y económica, los hombres los tomaron de los libros latinos precipitadamente $\mathrm{y}$ antes de tiempo. El jurista occidental se hace filólogo y sustituye la experiencia práctica de la vida por una experiencia erudita, fundada en el puro análisis y alcance de los conceptos jurídicos, los cuales a su vez, descansan sobre sí mismos. Esta ha sido la causa de que hayamos olvidado por completo que el derecho privado debe representar el espíritu de la existencia social y económica.. La formación de nuestros juristas y la literatura jurídica de nuestro tiempo cierran el camino a todo vislumbre de esa "fuente" del derecho vigente, que es en verdad su origen propio" (97).

De aquí que actualmente se insista por algunas tendencias en considerar al derecho como una ciencia social, en el sentido moderno, o como operativo, funcional, instrumental, para logros de los fines sociales. Un orden formalista olvida los 'contenidos' siempre cambiantes del derecho y 'establece' un sistema 'cierto' y 'seguro' y hasta cierto grado 'incambiable' y por lo tanto 'previsible' al cual se amoldan todos los miembros de la comunidad y por eso se exige "un libro que valga de hoy en adelante para siempre y quiere un sistema que prevea todos los casos posibles" (98).

Es evidente que nuestra tradición de 'derecho escrito' encaja perfectamente en una concepción formalista,

los conceptos eternamente válidos. Pero nos lo hace valioso la relación entre la existencia romana y los conceptos jurídicos romanos. Por el derecho romano podemos aprender a producir nuestro propio derecho, con nuestra propia experiencia". SPENGLER, op. cit., pág. 103.

97 SPENGLER, O., op. cit., pág. 99.

98 Ibídem. El problema de la 'seguridad' y 'previsión' que se establece en un sistema jurídico codificado se antepone como fuerte argumento a la inseguridad de los sistemas no codificados; sin embargo tal sistema ha dado en la práctica resultados que en nada muestran tal inseguridad; como afirma L. MAYERS,

"Actualmente aunque la codificación tiene sus defensores, especialmente en los círculos académicos, puede decirse con cierta exactitud que no hay ningún movimiento apreciable para una codificación 
privadista y dispositivista del derecho y del proceso. Pero aunque se le dé al juez una 'guía' por la que deba conducirse dentro del proceso dispositivo, no podemos seguir manteniendo al juez abstraído de los contenidos que se discuten en el litigio y sostener algo en lo que "ya nadie cree", es decir

"que las operaciones realizadlas por el Juez para interpretar el derecho son exclusivamente operaciones lógicas en el sentido estricto de las palabras, es decir, operaciones de deducción de ciertas conclusiones a partir de determinadas premisas; con otras palabras, que la actividad del juez es meramente mecánica o automática. Los juristas y los filósofos del derecho prestan cada vez más atención a la presencia manifiesta u oculta, consciente e inconsciente de los juicios de valor" (99).

Si tales juicios de valor constituyen la fuerza de convicción de la sentencia, y éstos deben objetivarse cuando "la sentencia judicial ajusta su valoración a patrones históricos vigentes" (100), entonces abrir al juzgador las posibilidades de inquirir por la verdad de los hechos en el proceso civil no significa más que la sentencia esté sólidamente fundamentada en función de esa investigación. De esta manera se puede librar

comprensiva en los círculos profesionales, judiciales ni legislativos. Aunque el sistema actual es indiscutiblemente imperfecto $y$ aparentemente anticientífico. puede decirse que en general ha demostrado que se puede trabajar con él, que no insume tiempo y que tampoco produce demasiada incertidumbre, como han sostenido muchos de sus críti$\cos "$,

El sistema legal de los Estados Unidos, Ed. Bibliográfica Argentina, 1958, pág. 345.

99 BOBBIO, Norberto, El problema del positivismo jurídico, Ed. EUDEBA, Bs. As., 1965, pág. 28.

100 Por aquí se vislumbra un concepto metodológico del proceso que pueda eliminar el fundamento 'político' de la posición del juez en el proceso civil y en extremo, del proceso en general; éste es el sentido de la tesis del autor Determinación y fundamento de la verdad como concepto estructural del Proceso Civil; COSSIO, Carlos, Teoría de la Verdad Jurídica, Bs. As., Ed. Losada, 1954, pág. 246. al juez de una actividad meramente "administrativa" y lograr que el juez moralmente capacitado, estrictamente seleccionado y cultural y jurídicamente preparado constribuya a enriquecer nuestra jurisprudencia, a elevar el nivel de nuestra ciencia jurídica.

El nuevo Código de Procedimientos Civiles no debe olvidar los problemas que hemos expuesto y que serias consideraciones hacen aconsejable que se adopte el principio inquisitorio en el proceso civil (101).

101 Por razones de la intención del artículo y de espacio sólo referiremos brevemente lo planteado desde el punto de vista de la facultad inquisitoria del juez. en el Perú. La comisión reformadora del código de procedimientos civiles de enero de 1949 propone mantener las formas esenciales del código de 1852 pues una "construcción como ésta no podría ser demolida sin causar graves daños a la vida jurídica del país". Tal proyecto fue obra de los "procedimentalistas", como los llama Ricardo Bustamante Cisneros, quien además lamenta que profesores universitarios, jueces y abogados "no se han preocupado de precisar, con críterio exegético ni con criterio sistemático, aquello que debe perdurar... y lo que puede desaparecer por la decantación histórica ya producida" (La reforma procesal en el Perú". Rev. El Foro. № 1, Año XXVI, Enero-Marzo 1949, pág. 18). Mario Alzamora Valdez trata el tema en su ponencia ante el Congreso Internacional de Juristas de 1951 en Lima, titulada "La verdad y el proceso civil" aunque refiriéndose principalmente al proceso simulado y propugna que la estructura formal del proceso "coincida con una relación real". En su Teoría general del Proceso de 1959 vuelve a tomar la misma posición que también es expresada en las sesiones de la Comisión reformadora del código de procedimientos civiles de 1964. Fuera de lo expresado se han levantado débiles voces exigiendo mayor actividad del juez dentro del proceso civil en relación a la verdad de los hechos. Si bien nuestro actual código le otorga al juez facultades para lograr una mejor apreciación de los hechos por medio de su art. 340, sin embargo esto se ve limitado por todo el sistema dispositivo del código, y por la concepción privadista del proceso que tienen los mismos jueces y abogados. En la Ley Orgánica del Poder Judicial se encuentran otros artículos que manifestarían una posibilidad inquisitoria, son el art. 25, el art. 140 inc. 2 y el art. 185 inc. 4 . 